\title{
Interactive comment on "Equatorward
} phytoplankton migration during a cold spell within the Late Cretaceous supergreenhouse" by Niels \section{A.G.M. van Helmond et al.}

Niels A.G.M. van Helmond et al.

n.vanhelmond@uu.nl

Received and published: 11 April 2016

We thank Dr. Schiøler for his positive review on our manuscript. As he notes, we have incorporated the comments and suggestions he raised in his review on an earlier version of the manuscript for a different journal.

Sincerely,

On behalf of all authors,

Niels van Helmond 